\title{
Early and Late Complications of Germinal Matrix-Intraventricular Haemorrhage in the Preterm Infant: What Is New?
}

\author{
Annemieke J. Brouwer Floris Groenendaal Manon J.N.L. Benders \\ Linda S. de Vries \\ Department of Neonatology, Wilhelmina Children's Hospital, University Medical Centre Utrecht, \\ Utrecht, The Netherlands
}

\section{Key Words}

Cranial ultrasound $\cdot$ Germinal matrix-intraventricular haemorrhage · Low-grade/severe germinal matrix-intraventricular haemorrhage $\cdot$ Magnetic resonance imaging · Preterm infant

\begin{abstract}
Germinal matrix-intraventricular haemorrhage (GMH-IVH) remains a serious problem in the very and extremely preterm infant. This article reviews current methods of diagnosis, treatment and neurodevelopmental outcome in preterm infants with low-grade and severe GMH-IVH. We conclude that there is still no consensus on timing of intervention and treatment of infants with GMH-IVH, whether or not complicated by post-haemorrhagic ventricular dilatation. The discrepancies between the studies underline the need for international collaboration to define the optimal strategy for these infants.

c) 2014 S. Karger AG, Basel
\end{abstract}

Presented at the International Symposium 'VIIth Recent Advances in Neonatal Medicine', Würzburg, 2014.

\section{Introduction}

Cranial ultrasound (cUS) has been used since the late 70 s to diagnose germinal matrix-intraventricular haemorrhage (GMH-IVH) and even though magnetic resonance imaging (MRI) is increasingly being used, cUS is still the most readily available and commonly used neuroimaging technique in the neonatal intensive care unit. The classification of Papile et al. [1] is still most often used to grade the severity of GMH-IVH, but most prefer to describe a parenchymal haemorrhage as a periventricular haemorrhagic infarction (PVHI) or venous infarction rather than a grade IV haemorrhage. Most studies regarding GMH-IVH are about preterm infants with a severe haemorrhage (grade III and PVHI), and this is likely for two reasons. Firstly, these lesions are reliably recognised with cUS [2]. Secondly, these larger lesions are more often related to an adverse neurological outcome [3].

The smaller lesions (grade I-II) are more difficult to diagnose with cUS and the inter-observer agreement tends to be poor with a $\kappa$ of $0.20-0.26$ [2]. Associated subtle white matter injury may be present, but is not always recognised with cUS. Kuban et al. [4] reported that the presence of ventriculomegaly was common in preterm infants with an IVH and more recently van Wezel-Meijler

\section{KARGER}

(C) 2014 S. Karger AG, Basel

1661-7800/14/1064-0296\$39.50/0

E-Mail karger@karger.com

www.karger.com/neo
L.S. de Vries, MD, PhD

Department of Neonatology, Wilhelmina Children's Hospital

University Medical Centre, Room KE 04.123.1

PO Box 85090, NL-3508 AB Utrecht (The Netherlands)

E-Mail l.s.devries@umcutrecht.nl 

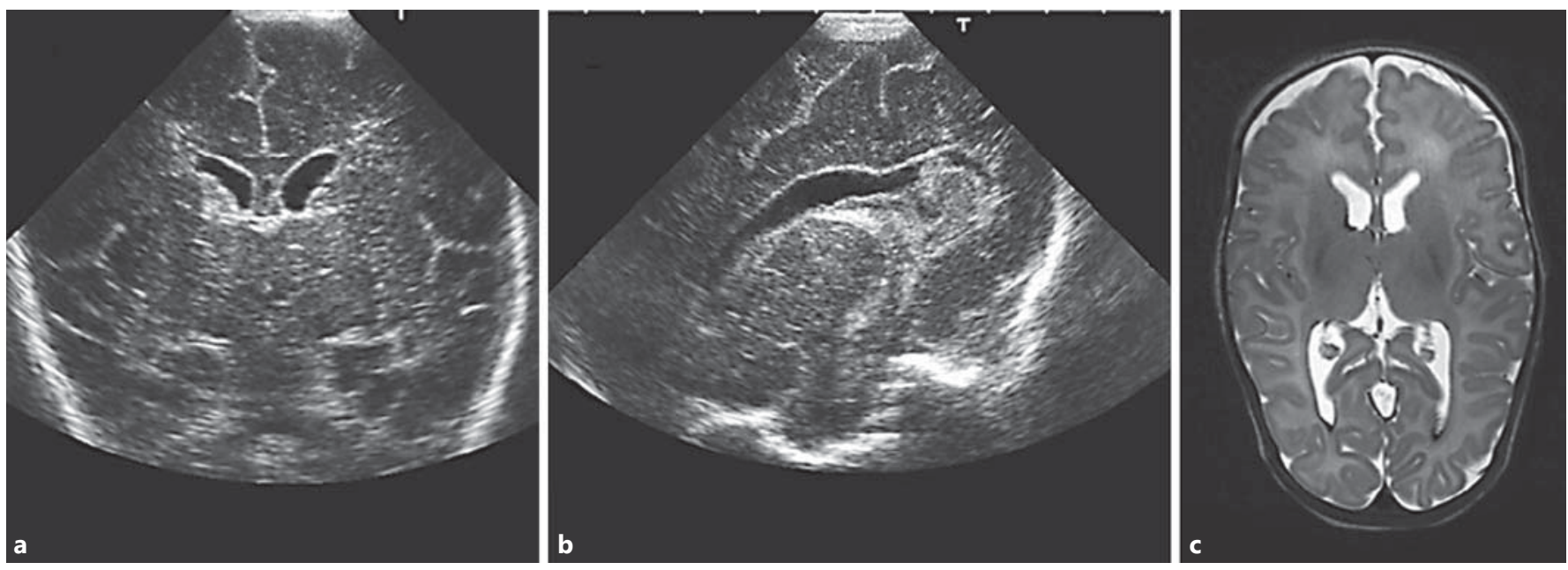

Fig. 1. Coronal view using the anterior fontanelle (a) and parasagittal view using the posterior fontanelle during the 1st week (b). The axial T2-weighted MRI at TEA no longer shows a dilated occipital horn and just a small amount of blood (seen as low signal intensity in both occipital horns; c).

et al. [5], using serial cUS and term equivalent age (TEA)MRI, reported that the presence of a low-grade GMHIVH was highly predictive of white matter abnormalities on TEA-MRI. The true impact of low-grade GMH-IVH on the neurodevelopment of extremely and very preterm infants is therefore not well known and the few available studies in the literature looking at neurodevelopmental outcome show conflicting data [6-9].

This review will discuss how low-grade GMH-IVH can be diagnosed more reliably and will review recent outcome data. Subsequently, we will discuss the diagnosis of severe GMH-IVH, the role of additional diagnostic methods, timing of intervention and neurodevelopmental outcome [10].

\section{Low-Grade GMH-IVH}

Any haemorrhage in the preterm infant typically has its onset in the germinal matrix, also known as the ganglionic eminence, which is the source of future neuronal and glial cells in the immature brain [11, 12]. The vasculature in the germinal matrix is very fragile and combined with the lack of cerebral autoregulation in many of these sick preterm infants and fluctuations in cerebral blood flow, it is not surprising that these vessels will rupture, which results in haemorrhage either restricted to the germinal matrix but more often also extends to the lateral ventricle [13].

Early and Late Complications of GMH-IVH

\section{Diagnosis}

With the use of cUS it can be difficult to make a distinction between an isolated GMH and an associated small IVH. Sometimes, the presence of blood in the ventricle may become clear after some time due to either mild post-haemorrhagic ventricular dilatation (PHVD) or due to increased echogenicity of the lining of the ependyma. Using the posterior fontanelle as an additional acoustic window, the diagnosis can be made more reliably [14]. This distinction can also be made with MRI and more small GMHs may be recognised, especially in the temporal horn, where it may be more difficult to have a good field of view using cUS. A relatively new MR sequence, susceptibility-weighted imaging (SWI), has also been reported to be very useful in the diagnostic process of these GMHs. Using cUS, 15 out of 60 infants were considered to have a GMH, but using MRI including SWI, 25 out of 60 were diagnosed to have a GMH [15]. A similar observation was reported by Intrapiromkul et al. [16]. In addition to a GMH, it is not uncommon to find additional, usually more subtle white matter lesions, mostly punctate white matter lesions using MRI. While these lesions are easy to recognise with MRI, they are often, but not always, recognised as inhomogeneous echogenicity on cUS [17]. One should also be aware of the fact that an MRI at TEA may no longer be able to assess the initial grade of the GMH-IVH. It is not uncommon to see no or only a very small amount of blood in the occipital horn with or without some degree of ventriculomegaly (fig. 1). 

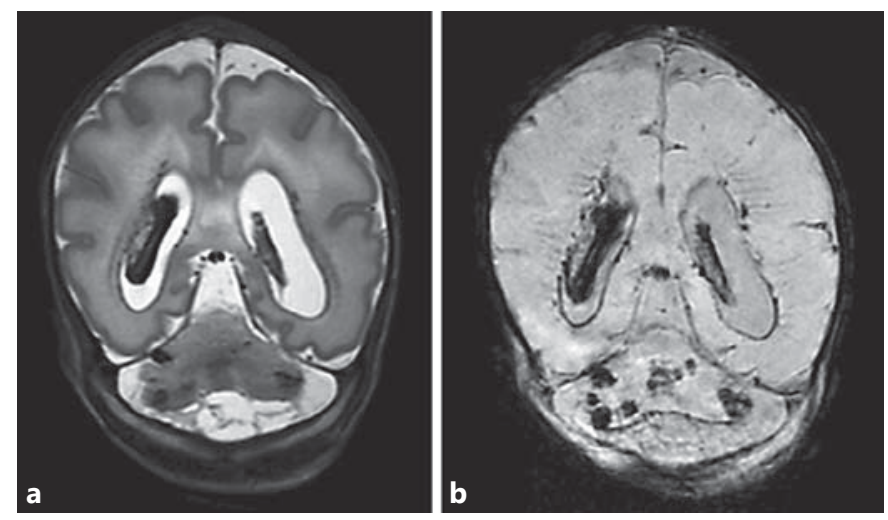

Fig. 2. MRI, coronal T2-weighted image (a), showing an IVH of grade II with mild PHVD but extensive haemorrhagic lesions in the cerebellum, which are also clearly seen with SWI (b).
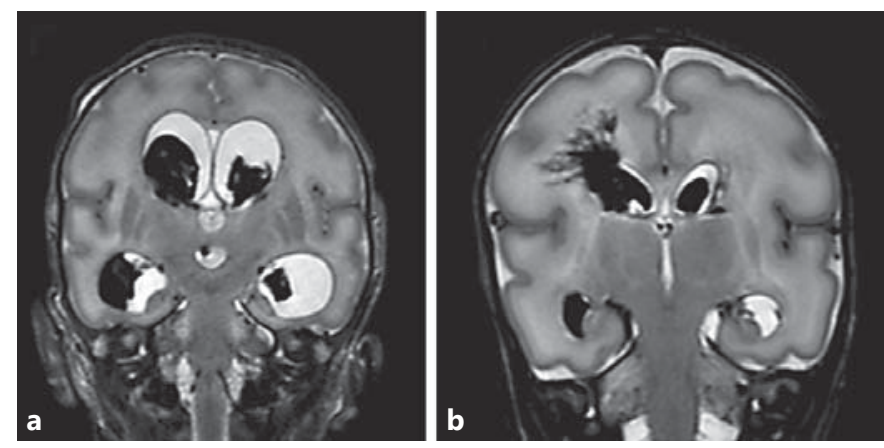

Fig. 3. MRI, coronal T2-weighted images. a Preterm infant, GA 29 weeks, MRI day 10, showing a grade III haemorrhage with PHVD and ballooning shape of the ventricles. Note the lack of extracerebral space. b Preterm infant, GA 28 weeks, MRI day 14, showing a PVHI with the typical triangular shape with the apex at the border of the right ventricle.

\section{Relation to Neurodevelopmental Outcome}

Most of the studies relating low-grade GMH-IVH with outcome are about preterm infants in whom the initial diagnosis was made using cUS. It is not clear from these studies whether the diagnosis, low-grade GMH-IVH, also took into account whether there were associated white matter lesions. The latter may have been more important with regard to later outcome than the GMH itself, but may be easily overlooked in the absence of an additional MRI. It is possible that these infants also had small cerebellar lesions, which may have played a role, but were not diagnosed using cUS. In one study, the diagnosis of a lowgrade GMH-IVH was made with cUS, and the TEA-MRI showed reduced cortical volume [18].
In the EPIPAGE study, 6.8 and $8.1 \%$ of infants with a grade I and II GMH-IVH, respectively, developed cerebral palsy (CP) based on cUS rather than MRI data [7]. In another large cohort, no difference was found between those without a haemorrhage and those with a grade I-II GMHIVH [8]. In this study, there was quite a high percentage of infants who developed CP, 8 and $9 \%$ of infants without or with a grade I and II GMH-IVH, respectively, which was likely to be explained by associated white matter injury not recognised with cUS. A third study reported outcome on an Australian cohort consisting of more than 2,000 preterm infants, with 515 (21.3\%) infants with a grade I-II GMH-IVH diagnosed with cUS. The authors reported increased rates of neurosensory impairment, developmental delay, CP (10.4\%) and deafness at 2-3 years of corrected age in those with a grade I-II GMH-IVH. The $\mathrm{CP}$ rate was quite high (6.8\%) in those without cUS abnormalities [9]. Compared to these studies, the CP rate of 35 and $55 \%$ for preterm infants with a gestational age (GA) below 28 weeks with a grade I and II GMH-IVH, respectively, was very high in the study by Klebermass-Schrehof et al. [19]. Even for those with a GA of 28-32 weeks, the $\mathrm{CP}$ rates of 12.5 and $23.0 \%$ for grade I and II GMH-IVH, respectively, are higher than reported so far. In our own cohort of 705 infants (2008-2011) with a GA of 30 weeks or less, $78(26.0 \%)$ showed a grade I or II haemorrhage on cUS and 0 and $4.0 \%$, respectively, developed CP. In 1 of the 3 infants with $\mathrm{CP}$, this could be explained by associated cystic periventricular leukomalacia not seen with cUS, the second had moderate PHVD (fig. 2) and in the third, adverse motor outcome could be explained by noncystic white matter injury.

Looking at these studies, it is clear that we need to look at a prospectively enrolled cohort of preterm infants, studied with serial cUS and early MRI, in order to study the effect of an isolated GMH-IVH and to find out how many of such a cohort do indeed have an isolated low-grade GMHIVH and how many have a low-grade GMH-IVH with associated subtle white matter and/or cerebellar lesions.

\section{Severe GMH-IVH}

The incidence of moderate-severe GMH-IVH has remained more or less the same over the last 2 decades [20, 21]. The proportion of severe GMH-IVH is especially large among the more immature infants with the incidence being inversely related to GA and birth weight [22]. A grade III is defined as a large IVH filling the ventricle by more than $50 \%$ with blood and resulting in dilatation in the acute stage. In approximately $15 \%$ of very low birth weight $(<1,500 \mathrm{~g})$ infants, the GMH-IVH is associated 
Table 1. Neurodevelopmental outcome: IVH grade I and II

\begin{tabular}{|c|c|c|c|c|}
\hline & $\mathrm{n}$ & Normal cUS & Grade I-II & Outcome \\
\hline Vasileiadis et al. [18], 2004 & $23 ;<1,500 \mathrm{~g}$ & 22 & 11 & $16 \%$ reduction in cerebral CGM volume at near-term age \\
\hline Scherlock et al. [47], 2005 & $\begin{aligned} 270 & ;<1,000 \mathrm{~g} \\
\text { or } & <28 \text { weeks }\end{aligned}$ & 180 & 72 & $\begin{array}{l}\text { At } 8 \text { years; CP: normal cUS: } 6.7 \% \text {; grade I: } 6.4 \% \text {; } \\
\text { grade II: } 24 \%\end{array}$ \\
\hline Patra et al. [6], 2006 & $490 ;<1,000 \mathrm{~g}$ & 258 & 104 & $\begin{array}{l}\text { CP: normal cUS: } 3 \% \text {; grade I-II: } 8 \% \text {; significantly lower } \\
\text { MDI and major neurologic abnormality ( } 13 \text { vs. } 5 \% \text { ) }\end{array}$ \\
\hline Beaino et al. [7], 2011 & 1,$812 ; \leq 32$ weeks & 1,153 & 290 & CP: normal cUS: 4\%; grade I: $8 \%$; grade II: $11 \%$ \\
\hline $\begin{array}{l}\text { Klebermass-Schrehof et al. } \\
\text { [19], } 2012\end{array}$ & $438 ;<32$ weeks & 287 & 121 & CP: normal cUS: $14.3 \%$; grade I: $34.8 \%$; grade II: $55 \%$ \\
\hline Payne et al. [8], 2013 & 1,$472 ;<27$ weeks & 1,021 & 270 & CP: normal cUS: $8 \%$; grade I-II: 9\% \\
\hline Bolisetty et al. [9], 2014 & 2,$414 ;<1,000 \mathrm{~g}$ & 1,043 & 336 & CP: normal cUS: $6.5 \%$; grade I-II: $10.4 \%$ \\
\hline UMCU & $705 ; \leq 30$ weeks & 296 & $\begin{array}{l}89 \\
(4 \text { died })\end{array}$ & Grade I: none; grade II: 3.5\% \\
\hline
\end{tabular}

CGM = Cortical grey matter; MDI = mental developmental index; UMCU = University Medical Centre Utrecht.

with parenchymal involvement of grade IV, preferably referred to as PVHI (fig. 3). There are three neuropathological consequences of IVH: (1) destruction of the germinal matrix [12], (2) associated white matter injury and (3) PHVD [22].

\section{Post-Haemorrhagic Ventricular Dilatation}

The most serious complication is the development of PHVD. PHVD occurs in $30-50 \%$ of all preterm infants with a grade III IVH or PVHI, and $25-30 \%$ of these develop progressive PHVD [23, 24]. The choice of intervention and the timing of neurosurgical intervention is still a matter of debate, as shown in a previous study [10] as well as in a European survey [25]. Currently, the prospective randomised controlled ELVIS trial (Early vs. Late Ventricular Index Study, trial No. ISRCTN43171322) is being conducted to assess the potential beneficial role of early intervention [i.e. initiated once the ventricular index (VI) has crossed the 97th centile according to Levene] over late intervention (i.e. initiated after the VI has exceeded the 97 th centile by $4 \mathrm{~mm}$ ). In this trial, the primary endpoint is death or the need for a ventriculoperitoneal (VP) shunt and the secondary endpoint neurodevelopmental outcome at 2 years of corrected age. In the ELVIS trial, timing of intervention is based on measurements, including the VI and anterior horn width, while others have looked, in a retrospective study, at the number of days after birth as a marker for early versus late treatment [26].

\section{Neuromonitoring}

Doppler ultrasound has been used to assess changes in cerebral haemodynamics in infants with ventricular dila- tation, showing an increase in the peak systolic flow velocity, followed by a decrease or absence of the end diastolic flow velocity [27-29]. Klebermass-Schrehof et al. [30] and Olischar et al. [31] have shown that an amplitude-integrated electroencephalography background pattern may deteriorate with progressive PHVD even before clinical deterioration occurs and before cUS measurements indicate the need for neurosurgical intervention. Only $23.5 \%$ of their infants showed a normal amplitude-integrated electroencephalography trace prior to intervention compared to $58.8 \%$ after the intervention. We were unable to reproduce these findings, which might be explained by our infants being more mature and undergoing earlier intervention [32].

Near-infrared spectroscopy may also be of value in optimising timing of intervention. Observational studies $[33,34]$ have shown low regional cerebral oxygenation $\left(\mathrm{rSO}_{2}\right)$ values in infants with PHVD with recovery following intervention. Further research is needed to prove that near-infrared spectroscopy can be used as an aid for optimising timing of intervention.

\section{Treatment}

Diagnostic and therapeutic approaches for PHVD are known to vary among neonatal centres [25]. In about 25\% of preterm infants with GMH-IVH and PHVD, insertion of a VP shunt is needed [24]. Neurosurgical intervention requires anaesthesia and daily punctures from the reservoir carry a risk of infection [35]. There may be complications, such as wound dehiscence or dysfunction requiring insertion of a second reservoir. Tapping a ventricular access device by a specially trained and dedicated team of 
Table 2. Neurodevelopmental outcome: IVH grade III and IV

\begin{tabular}{|c|c|c|c|c|}
\hline \multicolumn{5}{|l|}{ Grade III-IV } \\
\hline \multirow{2}{*}{$\begin{array}{l}\text { Adams-Chapman } \\
\text { et al. [3], } 2008 \\
\end{array}$} & \multirow{2}{*}{7,693} & \multirow{2}{*}{$\mathrm{BW}:<1,000 \mathrm{~g}$} & IVH III: $\mathrm{n}=459$ & MDI: 74.1; PDI: 77.4; CP: 23\% \\
\hline & & & IVH IV: $\mathrm{n}=311$ & MDI: 71.5; PDI: 73.2; CP: 37\% \\
\hline \multirow{2}{*}{$\begin{array}{l}\text { Brouwer et al. } \\
{[48], 2008}\end{array}$} & \multirow[t]{2}{*}{214} & \multirow[t]{2}{*}{ GA: $\leq 34$ weeks } & IVH III: $\mathrm{n}=94$ & Grade III, CP 5/68 (7.4\%); DQ >85: 61 (91\%) \\
\hline & & & IVH IV: $\mathrm{n}=120$ & Grade IV, CP 37/76 (48.7\%); DQ >85: 58 (79\%) \\
\hline Maitre et al. [49], & 69 & BW: $<1,500 \mathrm{~g}$ & Unilateral PVHI: $\mathrm{n}=52$ & MDI: 82; PDI: 53; CP (mild-severe): 67\% \\
\hline \multirow{2}{*}{$\begin{array}{l}\text { Vassilyadi et al. } \\
{[50], 2009}\end{array}$} & \multirow[t]{2}{*}{284} & Mean GA: 29 weeks & IVH III: $\mathrm{n}=43$ & Good outcome/mild impairment: $44 \%$ \\
\hline & & Mean BW: $1,320 \mathrm{~g}$ & IVH IV: $\mathrm{n}=54$ & Good outcome/mild impairment: $16 \%$ \\
\hline \multirow{4}{*}{$\begin{array}{l}\text { Klebermass-Schre- } \\
\text { hof et al. [19], } 2012\end{array}$} & \multirow[t]{4}{*}{438} & \multirow[t]{4}{*}{ GA: $<32$ weeks } & \multirow[t]{4}{*}{30} & CP: normal cUS: $14.3 \%$ \\
\hline & & & & CP grade III: $63.6 \%$; CP grade IV: $90.9 \%$ \\
\hline & & & & PDI/MDI <70: normal: 17.3/17.5\% \\
\hline & & & & Grade III: 70/60\%; grade IV: 85.7/62.5\% \\
\hline
\end{tabular}

Grade III-IV + PHVD

\begin{tabular}{|c|c|c|c|}
\hline $\begin{array}{l}\text { Adams-Chapman } \\
\text { et al. [3], } 2008\end{array}$ & $\begin{array}{l}76 \text { BW: }<1,000 \mathrm{~g} \\
93\end{array}$ & $\begin{array}{l}\mathrm{n}=103: \text { grade } \mathrm{III}+\text { shunt } \\
\mathrm{n}=125: \text { grade IV }+ \text { shunt }\end{array}$ & $\begin{array}{l}\text { MDI: 66.2; PDI: } 64.1 \text {; CP: } 57 \% \\
\text { MDI: 60.3; PDI: 55.2; CP: } 80 \%\end{array}$ \\
\hline $\begin{array}{l}\text { Bassan et al. [26], } \\
2012\end{array}$ & 32 GA: $<30$ weeks & $\begin{array}{l}\text { Early EVD ( } \leq 25 \text { days of life): } \\
\mathrm{n}=6 \text {, grade III; } \mathrm{n}=4 \text {, grade IV } \\
\text { Late EVD ( }>25 \text { days of life }): \\
\mathrm{n}=9 \text {, grade III; } \mathrm{n}=13 \text {, grade IV }\end{array}$ & $\begin{array}{l}\text { CP: } 70 \% \text {; Battelle total: } 93.2 \\
\text { CP: } 81.8 \% \text {; Battelle total: } 63.1\end{array}$ \\
\hline $\begin{array}{l}\text { Brouwer et al } \\
{[52], 2012} \\
\end{array}$ & 34 GA: $<32$ weeks & $\begin{array}{l}\mathrm{n}=17: \text { grade } \mathrm{III}+\mathrm{VD} \\
\mathrm{n}=17: \text { grade } \mathrm{IV}+\mathrm{VD}\end{array}$ & $\begin{array}{l}\text { Normal neurodevelopmental outcome: } 59.4 \% \text {; } \\
\text { CP: } 25 \% \text {; Mov-ABC <p5: 39\%; IQ mean: } 93\end{array}$ \\
\hline $\begin{array}{l}\text { inivasakumar } \\
\text { al. [51], } 2013\end{array}$ & 39 GA: $\leq 34$ weeks & $\begin{array}{l}\mathrm{n}=16:+\mathrm{TNP} \\
\mathrm{n}=12: \text { no TNP }\end{array}$ & $\begin{array}{l}\text { CCa: 77; MCb: 67; LCc: } 70 \\
\text { CCa: 90; MCb: 84; LCc: } 82\end{array}$ \\
\hline
\end{tabular}

CP: Bayley Scale of Infant Development III (18-24 months). BW = Body weight; CCa = cognitive composite score; DQ = development quotient; $\mathrm{EVD}=$ external ventricular drainage; $\mathrm{LCc}=$ language composite score; $\mathrm{MCb}=$ motor composite score; $\mathrm{MDI}=$ mental developmental index; Mov-ABC = movement $\mathrm{ABC}$ test; PDI = physical developmental index; $\mathrm{VD}=$ ventricular device.

neonatal staff, including doctors, physician assistants and nurses, may produce the lowest infection rate as well as a reliable schedule of tapping [36]. A wide range of ventricular access device- or VP shunt-related infections has been reported by different groups [37-39]. The use of a ventriculosubgaleal shunt also has been shown to be effective in the treatment of PHVD [40-42]. Neurodevelopmental outcome is influenced by infection and revision rate of a VP shunt [43].

To reduce the risk of infection, antibiotics are administered prior to and 2-3 days following reservoir and shunt insertion. Promising results have been shown using antibiotic-impregnated shunts. Their introduction reduced the incidence of shunt infection [44-46]. Impregnation of ventricular access devices with antibiotics may become a reasonable option to minimise the risk of infection in these high-risk patients.

\section{Neurodevelopmental Outcome}

Outcome studies tend to be based on the severity of the haemorrhage (table 1). Some studies also take the development of PHVD and the need for neurosurgical intervention into account. The more immature the infant, the greater the risk of a severe haemorrhage. KlebermassSchrehof et al. [19] have shown that outcome was worse in preterm infants with GA below 28 weeks compared to those with GA between 28 and 32 weeks. Long-term functional outcome of preterm infants with severe GMHIVH has been reported by several groups (table 2) [4852]. 
Bassan et al. [53] developed a PVHI severity score related to risk factors and outcome. The severity of the score depended on different ultrasonographic characteristics; unilateral or bilateral PVHI (localised in 1 territory or extensive, involving 2-5 territories) and occurrence of a midline shift. A higher severity score predicted a worse outcome.

Neurodevelopmental outcome mainly depends on the presence of associated parenchymal involvement. This was supported by the data of Maitre et al. [49] showing that the majority of preterm infants with a bilateral PVHI have a very poor cognitive and motor outcome. Subsequent development of a unilateral spastic $\mathrm{CP}$ following parenchymal involvement can be reliably predicted when an MRI is performed at term-equivalent age. Infants with an asymmetry in myelination almost invariably developed unilateral spastic CP [54].

Progressive PHVD following severe GMH-IVH was shown to be associated with a three- to four-fold increase in neurodevelopmental delay [55]. The need for neurosurgical intervention was shown to be associated with a poorer neurodevelopmental outcome [51]. Infants with progressive PHVD who received a temporising neurosurgical procedure (TNP) had worse outcomes compared with infants whose PHVD stabilised and needed no TNP. Srinivasakumar et al. [51] also suggest that increasing ventricular dimensions; anterior horn width, thalamooccipital distance and VI may inversely affect neurodevelopmental outcome.
In the small population of Bassan et al. [26], the impact of external ventricular drainage timing on long-term neurodevelopmental outcome revealed that infants who received this drainage early (before day 25 after birth) had a better score on the Battelle Developmental Inventory at 6 years (median age). Preterm infants with PHVD and no initial parenchymal injury less often had reduced rates of cognitive, communication and social disabilities and also had a better motor outcome.

\section{Conclusion}

Despite improvements in neonatal care for preterm infants, there has not been a clear decline in the number of infants who develop a severe GMH-IVH. The neurodevelopmental outcome, especially in infants with a severe GMH-IVH, remains a cause for concern. There is still no consensus with regard to timing of intervention and treatment of infants with GMH-IVH who develop PHVD. The discrepancies between the studies underline the need for international collaboration to define the optimal strategy for these infants.

\section{Disclosure Statement}

The authors have no conflicts of interest to disclose.

\section{References}

1 Papile LA, Burstein J, Burstein R, Koffler H: Incidence and evolution of subependymal and intraventricular hemorrhage: a study of infants with birth weights less than 1,500 gm. J Pediatr 1978;92:529-534.

- 2 Hintz SR, Slovis T, Bulas D, Van Meurs KP, Perritt R, Stevenson DK, Poole WK, Das A, Higgins RD; NICHD Neonatal Research Network: Interobserver reliability and accuracy of cranial ultrasound scanning interpretation in premature infants. J Pediatr 2007;150:592596.

-3 Adams-Chapman I, Hansen NI, Stoll BJ, Higgins R; NICHD Research Network: Neurodevelopmental outcome of extremely low birth weight infants with posthemorrhagic hydrocephalus requiring shunt insertion. Pediatrics 2008;121:e1167-e1177.
4 Kuban K, Sanocka U, Leviton A, Allred EN, Pagano M, Dammann O, Share J, Rosenfeld D, Abiri M, DiSalvo D, Doubilet P, Kairam R, Kazam E, Kirpekar M, Schonfeld S: White matter disorders of prematurity: association with intraventricular hemorrhage and ventriculomegaly. The Developmental Epidemiology Network. J Pediatr 1999;134:539-546.

5 van Wezel-Meijler G, De Bruine FT, Steggerda SJ, Van den Berg-Huysmans A, Zeilemaker S, Leijser LM, van der Grond J: Ultrasound detection of white matter injury in very preterm neonates: practical implications. Dev Med Child Neurol 2011;53(suppl 4):29-34.

6 6 Patra K, Wilson-Costello D, Taylor HG, Mercuri-Minich N, Hack M: Grades I-II intraventricular hemorrhage in extremely low birth weight infants: effects on neurodevelopment. J Pediatr 2006;149:169-173.
Beaino G, Khoshnood B, Kaminski M, Marret S, Pierrat V, Vieux R, Thiriez G, Matis J, Picaud JC, Rozé JC, Alberge C, Larroque B, Bréart G, Ancel PY; EPIPAGE Study Group: Predictors of the risk of cognitive deficiency in very preterm infants: the EPIPAGE prospective cohort. Acta Paediatr 2011;100:370-378.

$>8$ Payne AH, Hintz SR, Hibbs AM, Walsh MC, Vohr BR, Bann CM, Wilson-Costello DE; Eunice Kennedy Shriver National Institute of Child Health and Human Development Neonatal Research Network: Neurodevelopmental outcomes of extremely low-gestationalage neonates with low-grade periventricularintraventricular hemorrhage. JAMA Pediatr 2013;167:451-459. 
9 Bolisetty S, Dhawan A, Abdel-Latif M, Bajuk B, Stack J, Lui K; New South Wales and Australian Capital Territory Neonatal Intensive Care Units' Data Collection. Intraventricular hemorrhage and neurodevelopmental outcomes in extreme preterm infants. Pediatrics 2014; 133:55-62.

10 de Vries LS, Liem KD, van Dijk K, Smit BJ, Sie L, Rademaker KJ, Gavilanes AW; Dutch Working Group of Neonatal Neurology: Early versus late treatment of posthaemorrhagic ventricular dilatation: results of a retrospective study from five neonatal intensive care units in The Netherlands. Acta Paediatr 2002; 91:212-217.

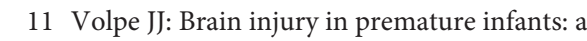
complex amalgam of destructive and developmental disturbances. Lancet Neurol 2009; 8:110-124.

$\checkmark 12$ Del Bigio MR: Cell proliferation in human ganglionic eminence and suppression after prematurity-associated haemorrhage. Brain 2011;134:1344-1361.

13 Kaiser JR, Gauss CH, Williams DK: The effects of hypercapnia on cerebral autoregulation in ventilated very low birth weight infants. Pediatr Res 2005;58:931-935.

14 Correa F, Enriquez G, Rossello J, Lucaya J, Piqueras J, Aso C, Vázquez E, Ortega A, Gallart A: Posterior fontanelle sonography: an acoustic window into the neonatal brain. AJNR Am J Neuroradiol 2004;25:1274-1282.

-15 Parodi A, Morana G, Severino MS, Malova M, Natalizia AR, Sannia A, et al: Low-grade intraventricular hemorrhage: is ultrasound good enough? J Matern Fetal Neonatal Med 2013, Epub ahead of print.

-16 Intrapiromkul J, Northington F, Huisman TA, Izbudak I, Meoded A, Tekes A: Accuracy of head ultrasound for the detection of intracranial hemorrhage in preterm neonates: comparison with brain MRI and susceptibility-weighted imaging. J Neuroradiol 2013;40:81-88.

$\checkmark 17$ Benders MJ, Kersbergen KJ, de Vries LS: Neuroimaging of white matter injury, intraventricular and cerebellar hemorrhage. Clin Perinatol 2014;41:69-82.

18 Vasileiadis GT, Gelman N, Han VK, Williams LA, Mann R, Bureau Y, Thompson RT: Uncomplicated intraventricular hemorrhage is followed by reduced cortical volume at nearterm age. Pediatrics 2004;114:367-372.

19 Klebermass-Schrehof K, Czaba C, Olischar M, Fuiko R, Waldhoer T, Rona Z, Pollak A, Weninger M: Impact of low-grade intraventricular hemorrhage on long-term neurodevelopmental outcome in preterm infants. Childs Nerv Syst 2012;28:2085-2092.

20 Fanaroff AA, Stoll BJ, Wright LL, Carlo WA, Ehrenkranz RA, Stark AR, Bauer CR, Donovan EF, Korones SB, Laptook AR, Lemons JA, Oh W, Papile LA, Shankaran S, Stevenson DK, Tyson JE, Poole WK; NICHD Neonatal Research Network: Trends in neonatal morbidity and mortality for very low birthweight infants. Am J Obstet Gynecol 2007;196:147. e1-147.e8.
21 van Haastert IC, Groenendaal F, Uiterwaal CS, Termote JU, van der Heide-Jalving M, Eijsermans MJ, Gorter JW, Helders PJ, Jongmans MJ, de Vries LS: Decreasing incidence and severity of cerebral palsy in prematurely born children. J Pediatr 2011;159:86-91.

22 Volpe J: Intracranial Hemorrhage: Germinal Matrix-Intraventricular Hemorrhage of the Premature Infant. Neurology of the Newborn, ed 5. Philadelphia, Saunders Elsevier, 2008, pp 517-588.

23 Murphy BP, Inder TE, Rooks V, Taylor GA, Anderson NJ, Mogridge N, Horwood LJ, Volpe JJ: Posthaemorrhagic ventricular dilatation in the premature infant: natural history and predictors of outcome. Arch Dis Child Fetal Neonatal Ed 2002;87:F37-F41.

24 Brouwer AJ, Groenendaal F, Han KS, de Vries LS: Treatment of neonatal progressive ventricular dilatation: a single-centre experience. J Matern Fetal Neonatal Med 2013, Epub ahead of print.

- 25 Brouwer AJ, Brouwer MJ, Groenendaal F, Benders MJ, Whitelaw A, de Vries LS: European perspective on the diagnosis and treatment of posthaemorrhagic ventricular dilatation. Arch Dis Child Fetal Neonatal Ed 2012; 97:F50-F55.

26 Bassan H, Eshel R, Golan I, Kohelet D, Ben Sira L, Mandel D, Levi L, Constantini S, BeniAdani L; External Ventricular Drainage Study Investigators: Timing of external ventricular drainage and neurodevelopmental outcome in preterm infants with posthemorrhagic hydrocephalus. Eur J Paediatr Neurol 2012;16: 662-670.

27 Van Bel F, Van de Bor M, Baan J, Stijnen T, Ruys JH: Blood flow velocity pattern of the anterior cerebral arteries. Before and after drainage of posthemorrhagic hydrocephalus in the newborn. J Ultrasound Med 1988;7: 553-559.

28 Nishimaki S, Iwasaki Y, Akamatsu H: Cerebral blood flow velocity before and after cerebrospinal fluid drainage in infants with posthemorrhagic hydrocephalus. J Ultrasound Med 2004;23:1315-1319.

29 Goh D, Minns RA: Intracranial pressure and cerebral arterial flow velocity indices in childhood hydrocephalus: current review. Childs Nerv Syst 1995;11:392-396.

-30 Klebermass-Schrehof K, Rona Z, Waldhor T, Czaba C, Beke A, Weninger M, Olischar M: Can neurophysiological assessment improve timing of intervention in posthaemorrhagic ventricular dilatation? Arch Dis Child Fetal Neonatal Ed 2012;98:F291-F297.

- 31 Olischar M, Klebermass K, Hengl B, Hunt RW, Waldhoer T, Pollak A, Weninger M: Cerebrospinal fluid drainage in posthaemorrhagic ventricular dilatation leads to improvement in amplitude-integrated electroencephalographic activity. Acta Paediatr 2009;98:1002-1009.

- 32 de Vries LS, Brouwer AJ, Groenendaal F: Posthaemorrhagic ventricular dilatation: when should we intervene? Arch Dis Child Fetal Neonatal Ed 2013;98:F284-F285.
33 Soul JS, Eichenwald E, Walter G, Volpe JJ, du Plessis AJ: CSF removal in infantile posthemorrhagic hydrocephalus results in significant improvement in cerebral hemodynamics. Pediatr Res 2004;55:872-876.

-34 van Alfen-van der Velden AA, Hopman JC, Klaessens JH, Feuth T, Sengers RC, Liem KD: Cerebral hemodynamics and oxygenation after serial CSF drainage in infants with PHVD. Brain Dev 2007;29:623-629.

35 Brouwer AJ, Groenendaal F, van den Hoogen A, Verboon-Maciolek M, Hanlo P, Rademaker KJ, et al: Incidence of infections of ventricular reservoirs in the treatment of post-haemorrhagic ventricular dilatation: a retrospective study (1992-2003). Arch Dis Child Fetal Neonatal Ed 2007;92:F41-F43.

36 Brouwer AJ, Groenendaal F, van den Hoogen A, de Vos JE, de Vries LS: Ventricular reservoir punctures performed by nurses: an improvement in quality of care. Neonatal Netw 2010;29:243-248.

37 Bruinsma N, Stobberingh EE, Herpers MJ, Vles JS, Weber BJ, Gavilanes DA: Subcutaneous ventricular catheter reservoir and ventriculoperitoneal drain-related infections in preterm infants and young children. Clin Microbiol Infect 2000;6:202-206.

38 Behjati S, Emami-Naeini P, Nejat F, El Khashab M: Incidence of hydrocephalus and the need to ventriculoperitoneal shunting in premature infants with intraventricular hemorrhage: risk factors and outcome. Childs Nerv Syst 2011;27:985-989.

- 39 Fulkerson DH, Vachhrajani S, Bohnstedt BN Patel NB, Patel AJ, Fox BD, Jea A, Boaz JC: Analysis of the risk of shunt failure or infection related to cerebrospinal fluid cell count, protein level, and glucose levels in low-birthweight premature infants with posthemorrhagic hydrocephalus. J Neurosurg Pediatr 2011;7:147-151.

40 Lam HP, Heilman CB: Ventricular access device versus ventriculosubgaleal shunt in post hemorrhagic hydrocephalus associated with prematurity. J Matern Fetal Neonatal Med 2009;22:1097-1101.

41 Rizvi SA, Wood M: Ventriculosubgaleal shunting for post-haemorrhagic hydrocephalus in premature neonates. Pediatr Neurosurg 2010;46:335-339.

42 Nagy A, Bognar L, Pataki I, Barta Z, Novak L: Ventriculosubgaleal shunt in the treatment of posthemorrhagic and postinfectious hydrocephalus of premature infants. Childs Nerv Syst 2013;29:413-418.

43 Kanev PM, Sheehan JM: Reflections on shunt infection. Pediatr Neurosurg 2003;39:285290.

44 Sciubba DM, Noggle JC, Carson BS, Jallo GI: Antibiotic-impregnated shunt catheters for the treatment of infantile hydrocephalus. $\mathrm{Pe}$ diatr Neurosurg 2008;44:91-96. 
-45 Parker SL, Attenello FJ, Sciubba DM, GarcesAmbrossi GL, Ahn E, Weingart J, et al: Comparison of shunt infection incidence in highrisk subgroups receiving antibiotic-impregnated versus standard shunts. Childs Nerv Syst 2009;25:77-83; discussion 85.

- 46 Parker SL, Anderson WN, Lilienfeld S, Megerian JT, McGirt MJ: Cerebrospinal shunt infection in patients receiving antibiotic-impregnated versus standard shunts. J Neurosurg Pediatr 2011;8:259-265.

47 Sherlock RL, Anderson PJ, Doyle LW, Victorian Infant Collaborative Study Group: Neurodevelopmental sequelae of intraventricular haemorrhage at 8 years of age in a regional cohort of ELBW/very preterm infants. Early Hum Dev 2005;81:909-916.

-48 Brouwer A, Groenendaal F, van Haastert IL, Rademaker K, Hanlo P, de Vries L: Neurodevelopmental outcome of preterm infants with severe intraventricular hemorrhage and therapy for post-hemorrhagic ventricular dilatation. J Pediatr 2008;152:648-654.
49 Maitre NL, Marshall DD, Price WA, Slaughter JC, O'Shea TM, Maxfield C, Goldstein RF: Neurodevelopmental outcome of infants with unilateral or bilateral periventricular hemorrhagic infarction. Pediatrics 2009; 124:e1153e1160.

50 Vassilyadi M, Tataryn Z, Shamji MF, Ventureyra EC: Functional outcomes among premature infants with intraventricular hemorrhage. Pediatr Neurosurg 2009;45: 247-255.

51 Srinivasakumar P, Limbrick D, Munro R, Mercer D, Rao R, Inder T, Mathur A: Posthemorrhagic ventricular dilatation - impact on early neurodevelopmental outcome. Am J Perinatol 2013;30:207-214.
52 Brouwer AJ, van Stam C, Uniken Venema M, Koopman C, Groenendaal F, de Vries LS: Cognitive and neurological outcome at the age of 5-8 years of preterm infants with posthemorrhagic ventricular dilatation requiring neurosurgical intervention. Neonatology 2012;101:210-216.

53 Bassan H, Benson CB, Limperopoulos C, Feldman HA, Ringer SA, Veracruz E, Stewart JE, Soul JS, Disalvo DN, Volpe JJ, du Plessis AJ: Ultrasonographic features and severity scoring of periventricular hemorrhagic infarction in relation to risk factors and outcome. Pediatrics 2006;117:2111-2118.

54 de Vries LS, van Haastert IC, Benders MJ, Groenendaal F: Myth: cerebral palsy cannot be predicted by neonatal brain imaging. Semin Fetal Neonatal Med 2011;16:279-287.

55 Persson EK, Hagberg G, Uvebrant P: Hydrocephalus prevalence and outcome in a population-based cohort of children born in 19891998. Acta Paediatr 2005;94:726-732. 